\title{
Analisis Komparatif Pendapatan Petani Pelaksana Pengelolaan Tanaman Terpadu Padi Sawah dengan Petani Non Pelaksana Pengelolaan Tanaman Terpadu Padi Sawah di Desa Pugaan Kecamatan Pugaan Kabupaten Tabalong
}

\section{(Comparative Analysis of Paddy Field Integrated Plants Management Income with Non Farmers in Paddy Integrated Planning Management in Pugaan Village Pugaan District Tabalong Regency)}

\author{
Azwar Saihani ${ }^{1)}$ \& As'ari' ${ }^{2)}$ \\ Program Studi Agribisnis, Sekolah Tinggi Ilmu Pertanian Amuntai \\ ${ }^{1)}$ Azwar.Saihani63@yahoo.com \\ 2)as’ari@gmail.com
}

\begin{abstract}
ABSTRAK
Tujuan penelitian ini adalah (i) untuk menganalisa berupa biaya dan penerimaan dari petani yang melaksanakan pengelolaan tanaman terpadu padi sawah dan yang tidak melaksanakan pengelolaan tanaman terpadu padi sawah di Desa Pugaan Kecamatan Pugaan (ii) mengetahui perbandingan pendapatan petani pelaksana pengelolaan tanaman terpadu padi sawah dengan yang tidak melaksanakan pengelolaan tanaman terpadu padi sawah di Desa Pugaan Kecamatan Pugaan. Penelitian ini dilaksanakan di Desa Pugaan Kabupaten Tabalong. Pemilihan petani sampel secara purposive sebanyak 23 orang untuk petani pelaksana padi sawah PTT dan secara acak sampel 23 orang petani petani non pelaksana beras PTT sawah. Data yang digunakan dalam penelitian ini berupa data primer dan data sekunder dikumpulkan dengan teknik wawancara, dan pencatatan survei. Pengelolaan tanaman in-temped (Padi sawah PTT) adalah inovasi baru untuk menyelesaikan berbagai masalah peningkatan produktivitas tanaman padi. Hasil analisis bahwa perataan rata dalam satu hektar adalah biaya untuk pelaksana PTT Rp. 20.046.618,45 dan kepada non pelaksana PTT Rp. 16.641.386,9, sedangkan hasil menghasilkan Rp. 22. 638.000 dan Rp. 17.801.640,85. Penghasilan untuk petani pelaksana PTT adalah Rp. 17.232.171,05 dalam satu hektar, untuk petani yang bukan pelaksana PTT adalah Rp. 12.755.601,16 dalam satu hektar. Dari hasil analisis disimpulkan bahwa perataan dalam satu hektar biaya, penerimaan dan pendapatan petani pelaksana PTT lebih tinggi daripada petani non pelaksana PTT.
\end{abstract}

Kata kunci: Analisis, PTT, biaya, penerimaan, pendapatan.

\begin{abstract}
This is research result with aim to for the cost analysis of, acceptance and comparison of earnings of farmer of executor of manajement of inwrought crop (PTT) by execute management of inwrought crop of rice field paddy. This research is executed by in Countryside of Pugaan Sub-Province of Tabalong. Election of farmer of sampel by purposive counted 23 people for the farmer of executor of PTT rice field paddy and by random sampling counted 23 people for farmer oflis non executor of PTT rice field paddy. Data which used in this research in the form of primary data and data of sekunder collected with interview technique, and record-keeping of survey. Management of inwrought crop ( Paddy rice field PTT) are new innovation to solve various problem of improvement of paddy crop productivity. Result of analysis of that flattening to flatten in one hectare is expense of for the executor of PTT Rp. 20.046.618,45 and to the non executor of PTT Rp. 16.641.386,9, while result produce $R p .22 .638 .000$ and Rp. 17.801.640,85. Earnings for the farmer of executor of PTT is Rp. 17.232.171,05 in one hectare, for farmer of non executor of PTT is Rp. 12.755.601,16 in one hectare. Of the analysis result concluded that flattening to flatten in one hectare of expense of, acceptance and earnings of farmer of executor of higher PTT than farmer of non executor of PTT.
\end{abstract}

Keywords: Analysis, PTT, expense of, acceptance, earnings. 


\section{PENDAHULUAN}

Pengembangan sektor tanaman pangan merupakan salah satu strategi kunci dalam memacu pertumbuhan ekonomi pada masa yang akan datang. Selain berperan sebagai sumber penghasil devisa yang besar, juga merupakan sumber kehidupan sebagian besar penduduk Indonesia (Kementerian Pertanian RI, 2014).

Komoditi tanaman pangan memiliki peranan pokok sebagai pemenuh kebutuhan pangan, pakan dan industri dalam negeri yang setiap tahunnya cendrung meningkat seiring dengan pertambahan jumlah penduduk dan berkembangnya industri pangan dan pakan sehingga dari sisi ketahanan pangan nasional fungsinya menjadi amat penting dan strategis.

Kabupaten Tabalong sebagian besar penduduknya bermata pencaharian sebagai petani. Komoditas yang diusahakan terutama tanaman perkebunan yaitu tanaman karet dan tanaman pangan yaitu tanaman padi. Hal ini sesuai dengan kondisi daerah yang merupakan dataran tinggi untuk wilayah bagian utara dan dataran rendah untuk wilayah selatan. Komoditas padi sawah terbayak di usahakan di daerah wilayah selatan yang meliputi Kecamatan Muara Harus, Kecamatan Kelua, Kecamatan Banua Lawas dan Kecamatan Pugaan. Sedangkan tanaman karet terbanyak diusahakanan di wilayah utara yang meliputi Kecamatan Bintang Ara, Kecamatan Haruai, Kecamtan Muara Uya, Kecamatan Jaro dan Kecamatan Tanjung. Untuk wilayah bagian utara merupakan potensi untuk sawah irigasi dan gogo. Sedangkan wilayah selatan merupakan sawah padi lebak dan sawah padi tadah hujan.

Dari luas lahan 394.600 hektar 9,32\% atau 36.789 hektar diantaranya adalah lahan sawah (BPS Tabalong, 2012). Dari 36.789 hektar lahan sawah yang diusahakan adalah 33.800 hektar. Berdasarkan data yang ada pada Dinas Tanaman Pangan Kabupaten Tabalong, perkembangan luas panen, produktivitas, dan produksi padi selama kurun waktu 5 tahun terakhir (2009 - 2013) pada Tabel 3 berikut :

Tabel 1. Perkembangan luas panen, produktivitas, dan produksi padi di Kabupaten Tabalong selama kurun waktu 5 tahun terakhir (Tahun 2009 - 2013)

\begin{tabular}{|c|c|c|c|c|c|c|c|c|}
\hline Thn & $\begin{array}{l}\text { Luas } \\
\text { tanam } \\
\text { (ha) }\end{array}$ & $\%$ & $\begin{array}{l}\text { Luas } \\
\text { Panen } \\
\text { (Ha) }\end{array}$ & $\%$ & $\begin{array}{c}\text { Pro } \\
\text { Vitas }\end{array}$ & $\%$ & $\begin{array}{l}\text { Produksi } \\
\text { (ton) }\end{array}$ & $\%$ \\
\hline 2009 & 27205 & & 27.205 & & 38,00 & & 103.379 & \\
\hline 2010 & 26960 & $(0,90)$ & 26.420 & $(2,88)$ & 47,25 & 24,34 & 124.835 & 20,75 \\
\hline 2011 & 27650 & 2,55 & 26.959 & 2,04 & 46,50 & $(1,59)$ & 125.358 & 0,42 \\
\hline 2012 & 27533 & $(0,42)$ & 26.847 & $(0,42)$ & 46,15 & $(0,75)$ & 123.897 & $(1,17)$ \\
\hline \multirow[t]{2}{*}{2013} & 28034 & 1,82 & 26.572 & $(1,02)$ & 43,40 & $(5,96)$ & 123.879 & $(0,02)$ \\
\hline & & 3,05 & & $(2,28)$ & & 16,04 & & 19,98 \\
\hline
\end{tabular}

Sumber : Dinas Tanaman Pangan, Peternakan dan Perikanan Kabupaten Tabalong (2013).

Tabel 1 menunjukan bahwa keadaan luasan panen, produktivitas dan produksi dari tahun 2009 sampai tahun 2013 cukup berfluktuasi. Namun secara umun rata rata mengalami peningkatan, kecuali luas panen menunjukan angka minus $2,28 \%$. Jumlah produktivitas mengalami peningkatan rata rata sebesar 16,04 persen dan produksi juga meningkat dengan rata rata 19,98 persen. Komoditas tanaman padi di Kabupaten Tabalong tersebar di semua wilayah kecamatan. Dari dua belas kecamatan yang ada, seluruhnya memiliki areal untuk komoditas tanaman padi sawah.
Tujuan dari penelitian ini adalah (i) untuk menganalisa berupa biaya dan penerimaan dari petani yang melaksanakan pengelolaan tanaman terpadu padi sawah dan yang tidak melaksanakan pengelolaan tanaman terpadu padi sawah di Desa Pugaan Kecamatan Pugaan (ii) mengetahui perbandingan pendapatan petani pelaksana pengelolaan tanaman terpadu padi sawah dengan yang tidak melaksanakan pengelolaan tanaman terpadu padi sawah di Desa Pugaan Kecamatan Pugaan.

METODE PENELITIAN 
Penelitian ini dilaksanakan di Desa Pugaan Kecamatan Pugaan Kabupaten Tabalong. Waktu penelitian dilaksanakan dari bulan April 2014 sampai selesai, mulai tahap persiapan, pengumpulan data, pengolahan data, sampai penulisan laporan. Jenis penelitian diskriftif, sumber data yang digunakan dalam penelitian ini meliputi data primer dan data sekunder serta studi pustaka. Data primer diperoleh dengan cara mengadakan wawancara langsung dengan petani responden dengan menggunakan daftar pertanyaan yang telah dipersiapkan sebelumnya. Sedangkan data sekunder diperoleh dari dinas atau instansi terkait yang ada keterkaitan dengan penelitian ini.

Pengambilan data dilakukan dengan cara menggunakan metode Multi Stage Sampling yaitu : 1. Purposive terdiri dari 7 kelompoktani Pelaksana PTT Padi Sawah, dimana sampel petani pelaksana pengelolaan tanaman terpadu diambil secara sengaja pada tiap kelompoktani yang ada didesa Pugaan, karena petani pelaksana pengelolaa tanaman terpadu hanya ada beberapa orang pada tiap kelompok tani. Sampel petani pelaksana pengelolaan tanaman terpadu diambil sebanyak 32 orang dari 7 kelompok tani yaitu dengan rincian sebagai berikut: Kelompok tani Beringin Jaya : 6 orang, Kelompok tani Telaga Harapan : 5 orang, Kelompok tani Jati Subur : 5 orang, Kelompok tani Harapan Makmur : 4 orang, Kelompok tani Bumi Kencana : 4 orang, Kelompok tani Sejahtera : 4 orang, Kelompok tani Padang Sari : 4 orang. 2. Random Sampling yaitu petani contoh non pelaksana pengelolaan tanaman terpadu diambil secara acak dari kelompok tani yang sama dan dengan jumlah yang sama dengan petani sampel pelaksana pengelolaan tanaman terpadu padi sawah.

\section{Biaya Produksi}

Untuk mengetahui tujuan pertama yaitu besarnya biaya produksi, penerimaan dan pendapatan digunakan perhitungan besarnya biaya total yang dikeluarkan petani. Secara matematis dinyatakan sebagai berikut :

$$
\mathrm{TC}=\mathrm{FC}+\mathrm{VC}
$$

Selain itu pula pembiayaan total digunakan perhitungan biaya eksplisit dan implisit yaitu digunakan rumus :

$$
\mathrm{TC}=\mathrm{TEC}+\mathrm{TIC}
$$

Biaya ekplisit adalah semua biaya yang secara nyata dikeluarkan oleh petani dalam penyelenggaraan usahataninya. Input input yang dibeli dari pihak lain adalah merupakan sumber bagi biaya ekplisit. Rumus yang digunakan untuk menghitung biaya ekplisit adalah dapat dirumuskan sebagai berikut (Kasim, 1995).

$$
\mathrm{TEC}=\sum_{i=1}^{n} \mathrm{EC}(\mathrm{i}=1,2,3 \ldots . \mathrm{n})
$$

Biaya implisit adalah biaya yang sifatnya diperhitungkan saja sebagai biaya, tidak benar benar merupakan pengeluaran yang dbayarkan secara nyata oleh petani. Untuk menghitung biaya implisit rumus yang digunakan adalah sebagai berikut ( Kasim, 1995):

$$
\mathrm{TIC}=\sum_{i=1}^{n} \mathrm{IC}(\mathrm{i}=1,2,3 \ldots . \mathrm{n})
$$

nilai harga persatuan produksi. Rumus untuk mengetahui penerimaan secara matematis dapat ditulis sebagai berikut (Kasim, 1995) :

$$
\mathrm{TR}=\mathrm{P} \times \mathrm{Q}
$$

Pendapatan adalah selisih antara penerimaan dengan biaya eksplisit total (biaya nyata yang dikeluarkan). Pendapatan yang diperoleh seorang petani adalah imbalan yang diperoleh keluarga petani dari pengguna faktor produksi, tenaga kerja dan modal yang diinvestasikan ke dalam bidang usaha (Kasim, 1995).

Untuk mengetahui pendapatan digunakan rumus (Kasim 1995) sebagai berikut :

$$
\mathrm{I}=\mathrm{TR} \text { - TEC }
$$

Input input yang berbentuk barang modal tetap yang tidak habis dipakai dalam satu kali proses produksi biayanya diperhitungkan sama dengan nilai penyusutannya. Rumus untuk menghitung biaya penyusutan barang dan modal dalam usaha pertanian padi selama satu periode produksi adalah :

$$
\text { Du }=\frac{\text { NB }- \text { NS }}{\text { UEB }} \times \text { Le }
$$

Untuk menjawab tujuan kedua yaitu dengan cara membandingkan pendapatan petani pelaksana pengelolaan tanaman terpadu padi sawah dengan non pelaksana pengelolaan terpadu padi sawah. Data disajikan dalam bentuk tabulasi sederhana. Dengan tabulasi sederhana dirasa sudah cukup untuk memenuhi tujuan penelitian (Soekartawi, 2011). 


\section{HASIL DAN PEMBAHASAN}

\section{Biaya Eksplisit}

Tabel 2. Biaya eksplisit rata-rata dalam satu hektar petani pelaksana dan non pelaksana pengelolaan tanaman terpadu (PTT) padi sawah di Desa Pugaan Kecamatan Pugaan

\begin{tabular}{clcccc}
\hline \multirow{2}{*}{ No } & \multirow{2}{*}{ Biaya Ekplisit } & \multicolumn{2}{c}{ PTT } & \multicolumn{2}{c}{ Non PTT } \\
\cline { 3 - 6 } & & $\begin{array}{c}\text { Jumlah Biaya } \\
(\mathrm{Rp}\end{array}$ & $\begin{array}{c}\text { Persentase } \\
(\%)\end{array}$ & $\begin{array}{c}\text { Jumlah Biaya } \\
(\mathrm{Rp}\end{array}$ & Persentase (\%) \\
\hline 1 & Biaya sewa lahan & $757.304,6$ & 13,77 & $814.628,20$ & 16,00 \\
2 & $\begin{array}{l}\text { Penyusutan alat \& } \\
\text { perlengkapan }\end{array}$ & $209.992,83$ & 5,48 & $202.493,3$ & 3,99 \\
3 & $\begin{array}{l}\text { Biaya sarana } \\
\text { produksi }\end{array}$ & $377.508,96$ & 6,86 & $280.105,63$ & 5,52 \\
4 & $\begin{array}{l}\text { Biaya tenaga kerja } \\
\text { luar keluarga } \\
\text { (TKLK) }\end{array}$ & $4.061 .021,51$ & 73,89 & $3.778 .890,00$ & 74,49 \\
\hline Jumlah & & & & \\
\hline
\end{tabular}

Berdasarkan Tabel 2 di atas, baik untuk pelaksana maupun non pelaksana pengelolaan tanaman terpadu, rata rata biaya eksplisit dalam satu hektar terbesar adalah biaya tenaga kerja luar keluarga (TKLK) yaitu sebesar Rp. 4.061.021,51/ dengan persentase $73,89 \%$ dan Rp. 3.778.890,00 atau $74,49 \%$ dan yang terkecil adalah biaya penyusutan alat dan perlengkapan yaitu sebesar Rp. 209.992,83 dengan persentasi 5,48\% dan Rp. 202.493,3 dengan persentasi 3,99\%.

\section{Biaya Implisit}

Biaya implisit merupakan biaya yang tidak dikeluarkan secara nyata oleh petani tetapi tetap diperhitungkan sebagai biaya. Biaya implisit pada pelaksanaan dan non pelaksanaan kegiatan pengelolaan tanaman terpadu adalah biaya biaya sewa lahan sendiri, sarana produksi (dana bantuan sosial),tenaga kerja dalam keluarga (TKDK) dan biaya bunga modal. Rincian biaya implisit ini dapat dilihat pada Tabel 3.

Tabel 3. Biaya implisit rata-rata per hektar pada pelaksana dan non pelaksana kegiatan pengelolaan tanaman terpadu (PTT) padi sawah di Desa Pugaan Kecamatan Pugaan

\begin{tabular}{clrccc}
\hline \multirow{2}{*}{ No } & \multicolumn{1}{c}{ Biaya Implisit } & \multicolumn{2}{c}{ PTT } & \multicolumn{2}{c}{ Non PTT } \\
\cline { 3 - 6 } & & $\begin{array}{c}\text { Jumlah Biaya } \\
(\mathrm{Rp})\end{array}$ & $\begin{array}{c}\text { Persentase } \\
(\%)\end{array}$ & $\begin{array}{c}\text { Jumlah Biaya } \\
(\mathrm{Rp})\end{array}$ & $\begin{array}{c}\text { Persentase } \\
(\%)\end{array}$ \\
\hline 1 & Biaya sewa lahan & $6.788 .695,34$ & 46,36 & $5.095 .682,5$ & 44,06 \\
2 & $\begin{array}{l}\text { Biaya sarana } \\
\text { produksi }\end{array}$ & $844.968,46$ & 5,77 & $713.076,27$ & 6,16 \\
3 & $\begin{array}{l}\text { Biaya tenaga kerja } \\
\text { dalam keluarga }\end{array}$ & $6.896 .523,28$ & 47.11 & $5.650 .774,65$ & 48,79 \\
4 & $\begin{array}{l}\text { (TKDK) } \\
\text { Bunga Modal }\end{array}$ & $112.408,84$ & 0,76 & $105.735,53$ & 0,91 \\
\hline Jumlah & 14.642 .790 & 100 & $11.565 .268,95$ & 100 \\
\hline
\end{tabular}

Berdasarkan Tabel 3 di atas, baik untuk pelaksana dan non pelaksana pengelolaan tanaman terpadu, biaya implisit terbesar adalah biaya tenaga kerja dalam keluarga yaitu sebesar Rp. $6.896 .523,28$ dengan persentase $47,11 \%$ dan Rp. 5.650.774,65 dengan persentase $48,79 \%$ dan yang terkecil adalah biaya bunga modal yaitu sebesar Rp. 112.603,39 dengan persentasi 0,76\% dan Rp. 104.467,23 dengan persentasi 0,91\%.

\section{Biaya Tetap}

Biaya tetap adalah biaya yang harus dikeluarkan, akan tetapi besar kecilnya biaya 
tidak dipengaruhi oleh besarnya produksi yang dicapai. Dalam usahatani padi, komponen biaya tetap terdiri dari biaya penyusutan alat dan perlengkapan, biaya tenaga kerja dalam keluarga (TKDK), biaya bunga modal dan biaya sewa lahan sendiri. Rincian biaya tetap rata-rata yang dikeluarkan petani responden dapat dilihat pada Tabel 4 berikut.

Tabel 4. Rincian biaya tetap perhektar untuk satu kali musim tanam pada petani pelaksana dan non PTT padi sawah di Desa Pugaan Kecamatan Pugaan

\begin{tabular}{clcccc}
\hline \multirow{2}{*}{ No } & \multicolumn{1}{c}{ Jenis biaya } & \multicolumn{2}{c}{ PTT } & \multicolumn{2}{c}{ Non PTT } \\
\cline { 3 - 6 } & & $\begin{array}{c}\text { Jumlah Biaya } \\
(\mathrm{Rp}\end{array}$ & $\begin{array}{c}\text { Persentase } \\
(\%)\end{array}$ & $\begin{array}{c}\text { Jumlah Biaya } \\
(\mathrm{Rp}\end{array}$ & Persentase (\%) \\
\hline 1 & Biaya sewa lahan & $6.788 .695,3$ & 48,46 & $5.095 .682,50$ & 46,09 \\
2 & $\begin{array}{l}\text { Penyusutan alat \& } \\
\text { perlengkapan }\end{array}$ & $209.992,83$ & 1,49 & $202.493,3$ & 1,83 \\
3 & $\begin{array}{l}\text { Biaya tenaga kerja } \\
\text { dalam keluarga }\end{array}$ & $6.896 .532,28$ & 49,25 & $5.650 .774,65$ & 51,13 \\
& $\begin{array}{l}\text { (TKDK) } \\
4\end{array}$ & $112.603,39$ & 0,80 & & \\
\hline Bunga Modal & $14.007 .814,4$ & 100 & $11.054 .685,9$ & 100 \\
\hline
\end{tabular}

Tabel 4 di atas memperlihatkan bahwa biaya tetap rata rata terbesar yang dikeluarkan pada kegiatan pengelolaaan tanaman terpadu adalah biaya tenaga kerja dalam keluarga dalam satu hektar permusim yaitu sebesar Rp. 6.896.532,28 dengan persentase 49,25\%, dan Rp. 5.650.774,65 dengan persentasi 51,13\% dan biaya tetap rata rata yang terkecil adalah biaya bunga modal yaitu sebesar Rp 112.603,4 dengan persentasi $0,8 \%$ dan Rp. 105.735 dengan persentasi $0,95 \%$.

\section{Biaya Variabel}

Biaya variabel adalah biaya yang harus dikeluarkan pada suatu usaha yang besar kecilnya tergantung pada jumlah produksi yang dicapai, biaya variabel juga mempunyai hubungan erat dengan besar kecilnya atau tinggi rendahnya output yang dihasilkan. Komponen biaya variabel pada usahatani padi terdiri atas biaya pupuk, biaya obat-obatan (herbisida, insektisida, ZPT), biaya benih, biaya tenaga kerja luar keluarga (TKLK). Rincian biaya variabel rata-rata yang dikeluarkan pada kegiatan kedua kegiatan ini dapat dilihat pada Tabel 5 berikut :

Tabel 5. Rincian biaya variabel rata rata perhektar pada kegiatan petani pelaksana dan non PTT padi sawah di Desa Pugaan Kecamatan Pugaan

\begin{tabular}{cccccc}
\hline \multirow{2}{*}{ No } & \multirow{2}{*}{ Jenis kegiatan } & \multicolumn{2}{c}{ PTT } & \multicolumn{2}{c}{ Non PTT } \\
\cline { 3 - 6 } & & $\begin{array}{c}\text { Jumlah Biaya } \\
(\mathrm{Rp}\end{array}$ & $\begin{array}{c}\text { Persentase } \\
(\%)\end{array}$ & $\begin{array}{c}\text { Jumlah Biaya } \\
(\mathrm{Rp}\end{array}$ & Persentase (\%) \\
\hline 1 & Biaya sewa lahan & $757.304,60$ & 12,38 & $814.628,20$ & 14,58 \\
2 & Biaya sarana produksi & $1.222 .477,42$ & 20,15 & $993.181,90$ & 17,78 \\
& $\begin{array}{l}\text { Biaya tenaga kerja luar } \\
3\end{array}$ & & & & \\
\hline & keluarga (TKLK) & $4.061 .021,51$ & 67,47 & $3.778 .890,85$ & 67,74 \\
\hline
\end{tabular}

Berdasarkan Tabel 5 di atas terlihat bahwa rata rata dalam satu hektar biaya variabel terbesar yang dikeluarkan petani pelaksana pengelolaan tanaman terpadu padi sawahadalah pada biaya TKLK yaitu sebesar Rp.4.061.021,51,- dengan persentase 67,47\% dan untuk non pengeloaan tanaman terpadu padi sawah adalah Rp. 3.778.890,85,- dengan persentase $67,70 \%$, sedangkan biaya variabel terkecil adalah biaya sewa lahan yaitu sebesar Rp. $757.304,60$ dengan persentase $12,38 \%$ dan $\mathrm{Rp}$. 814.628 .20 ,- dengan persentase $14,58 \%$.

\section{Biaya Total}


Dalam perhitungan dari kegiatan ini biaya total merupakan penjumlahan dari total biaya tetap dan total biaya variabel. Rincian biaya total rata-rata pada kegiatan ini dapat dilihat pada Tabel 6 berikut :

Tabel 6. Biaya total rata rata perhektar untuk satu kali musim tanam pada petani pelaksana dan non pelaksana pengelolaan tanaman terpadu padi sawah di Desa Pugaan Kecamatan Pugaan

\begin{tabular}{|c|c|c|c|c|c|}
\hline \multirow[b]{2}{*}{ No. } & \multirow[b]{2}{*}{ Jenis Kegiatan } & \multicolumn{2}{|c|}{ PTT } & \multicolumn{2}{|c|}{ Non PTT } \\
\hline & & $\begin{array}{c}\text { Jumlah Biaya } \\
\text { (Rp) }\end{array}$ & $\begin{array}{c}\text { Persentase } \\
(\%)\end{array}$ & $\begin{array}{c}\text { Jumlah Biaya } \\
\text { (Rp) }\end{array}$ & Persentase $(\%)$ \\
\hline 1 & Biaya tetap & $14.007 .814,87$ & 69,87 & 11054685,9 & 66,43 \\
\hline 2 & Biaya variable & $6.040 .803,58$ & 30,13 & 5.586 .700 & 33,57 \\
\hline Juml & biaya total/ha & $20.048 .618,45$ & 100 & 16.641386 & 100 \\
\hline
\end{tabular}

Berdasarkan Tabel 6 di atas, dalam satu hektar biaya terbesar yang harus dikeluarkan oleh petani responden pada pengelolaan tanaman terpadu dan non pengelolaan tanaman terpadu adalah biaya tetap yaitu sebesar Rp. 14.007.814,87,- atau sebesar 69,67\% dan Rp. 11.054.685 atau sebesar $66,43 \%$. Sedang biaya variabel hanya sebesar Rp 6.040.803,58 dan Rp. 5.586.700 dengan persentase sebesar 30,57\% dan dengan persentase $33,69 \%$.

\section{Penerimaan}

Penerimaan usahatani adalah besarnya produksi dari usahatani dikalikan dengan harga yang berlaku di tingkat petani. Produksi rata rata yang dihasilkan petani pelaksana pengelolaan tanaman terpadu padi sawah dan non pelaksana pengelolaan tanaman terpadu padi sawah dapat dilihat pada Tabel 7 berikut :

Tabel 7. Jumlah penerimaan rata rata dalam satu hektar untuk satu kali musim tanam pada petani pelaksana pengelolaan tanaman terpadu dan non pengelolaan tanaman terpadu padi sawah di Desa Pugaan.

\begin{tabular}{llcc}
\hline No & \multicolumn{1}{c}{ Uraian } & PTT & Non PTT \\
\hline 1 & Jumlah produksi GKG $(\mathrm{Kg})$ & 5390 & 4238,49 \\
2 & Harga (Rp/Kg) & 4200 & 4200 \\
3 & Jumlah penerimaan (Rp) & 22.638 .000 & $17.810 .640,85$ \\
\hline
\end{tabular}

Dari tabel di atas dapat dilihat bahwa jumlah produksi yang dihasilkan petani pelaksana pengelolaan tanaman terpadu padi sawah rata rata 5,39 ton GKG perhektar, dan jika di kalikan dengan harga sebesar Rp. 4200/kg maka diterima petani adalah Rp. 22.638.000,sedang produksi petani non pelaksana pengelolaan tanaman terpadu padi sawah rata rata adalah 4,238 ton GKG dalam satu hektar, dan penerimaan petaninya adalah $\mathrm{Rp}$. $17.810 .640,85$.

\section{Pendapatan}

Pendapatan usahatani adalah besarnya penerimaan (TR) dikurangi dengan biaya eksplisit (TEC). Pendapatan rata-rata petani PTT dan non pelaksana PTT dapat dilihat pada Tabel 8 berikut.

Tabel 8. Pendapatan rata-rata petani pelaksana pengelolaan tanaman terpadu dan petani non pelaksana pengelolaan tanaman terpadu dalam satu hektar selama satu musim tanam di Desa Pugaan Kecamatan Pugaan

\begin{tabular}{|c|c|c|c|c|}
\hline No. & Jenis Kegiatan & $\begin{array}{l}\text { Penerimaan } \\
\text { (TR) }\end{array}$ & $\begin{array}{l}\text { Biaya Eksplisit } \\
\text { (TEC) }\end{array}$ & Pendapatan $(\mathrm{Rp})$ \\
\hline 1 & Pengelolaan tanaman terpadu & 22.638 .000 & $5.405 .827,9$ & $17.232 .172,1$ \\
\hline 2 & Non pengelolaan tanaman terpadu & $17.801 .640,8$ & $5.076,117,9$ & $12.725 .522,8$ \\
\hline
\end{tabular}


Dari Tabel 8 diatas, jumlah pendapatan rata-rata petani pelaksana PTT sebesar Rp 17.232.172,1,- dalam satu hektar selama satu musim tanam dan petani non pelaksana PTT adalah Rp. 12.725,522,8, dalam satu hektar selama satu musim tanam.

\section{Analisis Pendapatan}

Dari hasil di atas komponen analisis dibedakan atas dua komponen yaitu :
1. Komponen biaya, meliputi: a) biaya tenaga kerja, b) saprodi, c) biaya sewa lahan d) biaya penyusutan alat dan e) biaya bunga modal.

2. Komponen pendapatan, meliputi: a) produksi b) harga gabah kering giling $(\mathrm{GKG}) \mathrm{c}$ ) penerimaan, d) pendapatan.

Secara rinci analisis pendapatan petani pelaksana pengelolaan tanaman terpadu dengan non pengelolaan tanaman terpadu disajikan pada Tabel 9 di bawah ini :

Tabel 9. Analisis perbandingan pendapatan petani pengelola tanaman terpadu dengan petani non pengelola tanaman terpadu padi sawah di Desa Pugaan

\begin{tabular}{lcc}
\hline Komponen biaya dan pendapatan & $\begin{array}{c}\text { Pengelolaan tanaman } \\
\text { terpadu (Rp) }\end{array}$ & $\begin{array}{c}\text { Non pengelolaan tanaman } \\
\text { terpadu (Rp) }\end{array}$ \\
\hline A. Biaya eksplisit & & \\
1. TK luar keluarga & $4.061 .021,51$ & $3.778 .890,85$ \\
2. Saprodi (swadaya) & $377.508,90$ & $280.105,63$ \\
3. Sewa Lahan & $757.034,6$ & $814.628,20$ \\
4. Penyusutan Alat & $209.992,83$ & $202.493,30$ \\
Jumlah & $5.405 .827,95$ & $5.076 .117,98$ \\
\hline B. Biaya impliSit & & \\
1. Sewa lahan & $6.778 .695,34$ & $5.095 .682,5$ \\
2. Saprodi (bansos) & $844.968,48$ & $713.076,27$ \\
3. TK dalam keluarga & $6.896 .523,28$ & $5.650 .774,6$ \\
4. Bunga modal & $112.603,39$. & $105.735,53$ \\
Jumlah & $14.642 .790,49$ & $11.565 .268,95$ \\
\hline C. Biaya total (A+ B) & $20.046 .618,45$ & $16.641 .386,94$ \\
\hline D. Penerimaan & & 4238,49 \\
1. Produksi (Kg) & 5390 & 4200 \\
2. Harga (Rp) & 4200 & $17.801 .640,85$ \\
Penerimaan (P.Q) & 22.638 .000 & $12.755 .601,16$ \\
\hline E. Pendapatan (TR-TEC) & $17.232 .172,05$ & \\
\hline
\end{tabular}

Tabel di atas menunjukan bahwa pada semua komponen biaya dan komponen penerimaan terjadi perbedaan antara pelaksana pengelolaan tanaman terpadu dengan non pelaksana pengelolaan tanaman terpadu. Perbedaan yang cukup jauh berbeda yaitu pada biaya tenaga kerja dalam keluarga dan tenaga kerja luar keluarga. Hal ini disebabkan oleh karena pada pelaksanaan pengelolaan tanaman terpadu menggunakan cara tanam jajar legowo. Cara ini lebih banyak memerlukan tenaga kerja (136,8 HOK/hektar) dibandingkan dengan cara tanam secara acak (102,7 HOK / hektar). Demikian pula halnya dengan biaya panen dan pasca panen. Penyebabnya adalah karena pada pelaksanaan pengelolaan tanaman terpadu hasil produksi lebih tinggi $(6489,1 \mathrm{~kg}$ GKP) sehingga perlu tenaga kerja lebih banyak dibandingkan dengan pada non pelaksana pengelolaan tanaman terpadu yang produksinya lebih rendah $(5098,35$ kg GKP).
Total biaya yang dikeluarkan pelaksana pengelolaan tanaman terpadu lebih besar dibandingkan non pelaksana pengelolaan tanaman terpadu yaitu sebesar Rp. 3.405.231,51,-, tapi hal ini diiringi dengan peningkatan produktivitas padi sebesar $1.390,75 \mathrm{~kg}$ GKP, sehingga diikuti dengan peningkatan pendapatan sebesar Rp. 4.533.918 dibandingkan dengan non pelaksana pengelolaan tanaman terpadu.

\section{KESIMPULAN}

Pengelolaan tanaman terpadu padi sawah di Desa Pugaan Kecamatan Pugaan rata-rata biaya tetap mencapai Rp. 14.007.814,87 dalam satu hektar permusim dan biaya variabel mencapai Rp. 6.040.803,58 dalam satu hektar permusim sehingga rata rata biaya totalnya dalam satu hektar mencapai Rp. 20.046.618,45 permusim tanam. Adapun penerimaan rata rata untuk petani pelaksana pengelolaan tanaman padi 
sawah permusim adalah Rp. 22.638.000,- dalam satu hektar, sedangkan non pengelolaan tanaman terpadu padi sawah di Desa Pugaan Kecamatan Pugaan rata rata biaya tetap permusim tanam mencapai Rp. 11.054.685,9 dalam satu hektar dan biaya variabel mencapai Rp. 5.586.700,9 satu hektar dalam satu musim tanam. Sehingga rata rata biaya totalnya mencapai Rp. 16.641.386,9 dalam satu hektar per musim tanam. Adapun penerimaan rata rata adalah Rp. 17.801.640,85,dalam satu hektar per musim tanam. Pendapatan petani pelaksana pengelolaan tanaman terpadu padi sawah rata rata dalam satu hektar adalah $\mathrm{Rp}$. 17.232.172,05,- permusim tanam dan pendapatan petani non pelaksana pengelolaan tanaman padi sawah rata rata dalam satu hektar adalah $\mathrm{Rp}$. 12.755.601,16,- per musim tanam. Dari data di atas dapat dilihat bahwa total biaya yang dikeluarkan petani pelaksana pengelolaan tanaman terpadu padi sawah lebih besar Rp. 3.405.231,51,- jika dibandingkan dengan biaya total petani non pelaksana pengelolaan tanaman terpadu padi sawah, tapi peningkatan biaya ini diikuti dengan peningkatan produktivitas hasil yaitu sebesar $1.390,75 \mathrm{~kg}$ GKP, yang ikut berdampak dengan peningkatan pendapatan petani pelaksana pengelolaan tanaman terpadu padi sawah yaitu sebesar Rp. 4.533.918,- jika dibandingkan dengan petani non pelaksana pengelolaan tanaman terpadu.

\section{DAFTAR PUSTAKA}

BPS Kabupaten Tabalong. 2013. Kabupaten Tabalong Dalam Angka Tahun 2012. Tanjung.

Kasim, A. 1995. Teori Pembuatan Keputusan. Jakarta: Fakultas Ekonomi Universitas Indonesia.

Kementerian Pertanian RI. 2014. Laporan Tahunan 2013. Jakarta.

Soekartawi. 2011. Ilmu Usaha Tani. Universitas Indonesia : Jakarta. 